\title{
Next Steps for Spatial Demography
}

\author{
Stephen A. Matthews ${ }^{1}$
}

Published online: 16 October 2019

๑) Springer Nature Switzerland AG 2019

I would like to open my first editorial by thanking the founding editors of Spatial Demography, Frank Howell and Jeremy Porter, and their editorial board for all their contributions over the past eight years. Frank and Jeremy recognized long before anyone else the importance of a signature journal for the field of spatial demography. I greatly appreciate the foundation they set and for initiating the later partnership with Springer. I was fortunate to have the opportunity to work with both Frank and Jeremy on an edited book and then more recently alongside Jeremy as co-editor of the journal. This was a valuable experience and certainly eased the transition to becoming sole editor. ${ }^{1}$

My primary goal as editor is to oversee the further maturation of the journal and specifically for it to become recognized as the leading outlet for the dissemination of high-quality, innovative, and exciting work in the field of spatial demography. Within my term as editor-in-chief my next steps will focus on expanding the journal from three to four issues per annum, with each issue containing six articles. The target of 24 articles per annum, plus other contributing materials within each issue, will help the journal secure an impact factor; an important next step towards journal maturity and heightened visibility. This is an ambitious short-term goal as to date the production schedule has been more erratic than predictable, and the 2019 volume is closing out with a combined issue $2 / 3$. There are undoubtedly challenges ahead but I firmly believe a target of four issues and 24 papers can be achieved. It might not be achieved quickly but this is my goal.

To achieve the stated goal it is incumbent on me as editor-in-chief to be proactive in advertising the journal, securing and inviting high quality submissions, and for overseeing a rigorous and fair review process. I have started this journey and as part of coming up to speed I also have started a dialogue on these topics within my

\footnotetext{
1 I am also indebted to John Iceland and Jenny Van Hook for being able to work alongside them for 3 years as co-editor of Demography.
}

Stephen A. Matthews

sxm27@psu.edu

1 Department of Sociology and Criminology, Department of Anthropology, and Graduate Program in Demography, The Pennsylvania State University, 601 Oswald Tower,

University Park, PA 16802, USA 
own professional networks, with Esther Otten and the staff at Springer, and with a newly formed editorial board. I am firmly committed to timely, rigorous, and fair reviews. My editorial approach or practice is to put myself in the position of the author and consider what they might hope for. Usually it is timeliness and fairness. In that regard I will be attentive to the time in and between all the transition stages that a submission might follow; periods of transitions that should be short duration but can easily become protracted and thereby unnecessarily extending the time to under review/to decision. That is, I will be attentive to the time between receipt and the decision whether the manuscript will be sent out for review, and the time spent securing reviewers. I will work with reviews as much as possible and be flexible ... but I will also expect adherence to agreed up on due dates; and, relatedly I will put extra effort in securing the last-to-be-submitted review. Moreover, I will write decision letters, with appropriate levels of guidance for the authors, as soon as possible after receipt of all reviews ... and then repeat the entire process for R\&Rs. As editor I will do all that I can to ensure that the review process is rigorous and fair. But, as editor I will not compromise on quality just to hit the target number of articles or page allocations. The next steps for the journal are not just about securing an impact factor but about the publication of high quality papers on route to securing an impact factor.

To help me in the task of maintaining the quality of the product that is produced I am particularly excited by those that have agreed to serve on the editorial board. The editorial board is drawn from all ranks of the profession, multiple disciplines, and includes researchers with diverse substantive interests and methodological skills. These researchers have experience in academic, public policy, and applied research and have made important contributions to conceptual, measurement, data, and method development within spatial demography. I am delighted that the new editorial board includes six women - an increase of six-but this is not enough and in the next steps I certainly look to increase the number. The new editorial board is also more geographically distributed than before which is as it should be in a truly international field like demography. I aim to improve on the international representation of too. For a complete list of the editorial board members please see the journal website (https://link.springer.com/journal/40980) and/or the inside cover of the print copy of the journal. ${ }^{2}$

The editorial board members have signed on to assist me in helping promote the journal and I am truly grateful. It is important that the journal leads the way and contributes to the discussions on the innovative frontiers in spatial demography and how these relate to broader themes in the parent discipline. At the time of writing, I am delighted that three editorial board members are developing ideas for special issues, and one has been advertised. Angelo Mazza (University of Catania, Italy) proposed and is organizing a special issue on "Exploiting Fine-scale Data in Modeling Migrants' Settlement Patterns." Others special issue announcements will follow. Please bookmark the journal's webpage at Springer for future announcements.

\footnotetext{
${ }^{2}$ Please do contact me with nominations, including self-nominations, for consideration to join the editorial board.
} 
One of the first next steps asked of me by Springer was to update the profile description on their webpage. I include the materials below. I hope it provides a general orientation to my own thinking and perspective on the field of spatial demography. Personally speaking, I do not see the description as controversial though others may place different weights on what could be prioritized or on what components to include in an academic journal that is designed to best serve the sub-field of spatial demography as well as attract demographers and researchers in the wider academy to our pages.

The overview paragraph reads:

"Spatial Demography focuses on understanding the spatial and spatiotemporal dimension of demographic processes. More specifically, the journal is interested in submissions that include the innovative use and adoption of spatial concepts, geospatial data, spatial technologies, and spatial analytic methods that further our understanding of demographic and policy-related related questions. The journal publishes both substantive and methodological papers from across the discipline of demography and its related fields (including economics, geography, sociology, anthropology, environmental science) and in applications ranging from local to global scale. In addition to research articles the journal will consider for publication review essays, book reviews, and reports/ reviews on data, software, and instructional resources."

To review some main themes, the focus is on the subject matter of interest to demographers. This will likely mean that submissions will be triaged if they are on substantive topics far removed from the home discipline of demography. As a rule of thumb if the subject matter is not part of the set that is typically covered by sessions at the Population Association of America (PAA) annual conference, those conferences supported by other international regional associations, or by the International Union of Scientific Study of Populations (IUSSP) and their scientific panels then the issue of fit will arise. ${ }^{3}$ I am aware that a field can and should evolve, that new theories, questions, data, and methods can emerge, and I will do my best to be accommodating but the journal needs a core focus, and that will be demography.

Spatial Demography is an interdisciplinary journal. I fully expect contributing authors to come from those who are self-identified as demographers but also the many related fields of study and thus to submit manuscripts on a diverse set of topics, including but not limited to core demographic processes such as fertility, migration, and mortality (past, present, and future) but also on topics as varied, and even as interconnected, as racial/ethnic segregation and other forms of social stratification and inequality, education, labor market and housing markets, health behaviors, morbidity and wellbeing, family structure/transitions, aging, intergenerational ties, and population-environment interactions. The focus here on substantive themes is not to limit or treat as secondary the fast-changing world of spatial method development and testing, the innovation in harnessing new kinds of geospatial data, the creation

\footnotetext{
${ }^{3}$ It should go without saying that a submission should have a 'spatial' component as this is a core criterion determining fit.
} 
of new measures, and how these methods, data, and measures are applied to and inform demographic research. Nor is there any intent to restrict studies motivated by the application of established spatial analytic methods. These are all welcome. As has already been implied the most important next step is to grow the visibility of the journal while maintaining quality. For me the most exciting papers to read and the ones I hope to publish in this journal will be those that involve high quality and rigorous research and that can offer new insights based on the innovative integration of spatial theories, concepts, data, measures, and analytical methods in both academic and policy research on demographic processes.

Demography is an inherently international field of study. Our science, questions, theories, and methods are not usually constrained by international boundaries. A personal next step is to be proactive in securing contributions from across the globe, both in terms of the geographic and topical coverage as well as the home institution and country of potential author(s). Despite good intentions this is not going to be an easy task. I hope to work with the editorial board, reviewers, and the readers in helping grow the international coverage and contributions appearing in the pages of the journal. ${ }^{4}$

As I assemble future issues of the journal the core components will be research articles. I will consider review essays and indeed plan to solicit a small number in the coming years. While such articles might be labelled as 'review' I intend that these are articles that for the most part look forward and focus on innovative frontiers, and challenges and opportunities ahead. I have re-started the book review section $^{5}$ and a useful feature introduced in the initial incarnation of the journal included reviews and reports on data and software and I plan to revive this. I welcome contributions on data and software as well as suggested topics for inclusion; and this would include discussions and reviews of instructional resources too (please note that I am currently exploring a special issue on instruction in spatial demography). Speaking of special issues these will likely stand alone in that they will typically include an introductory comment or editorial that will set the stage for the articles that follow. In this way the focus is on the main topic of interest. Only if relevant would a book review or other material be included in the same issue of the journal.

I know the next steps forward will be offset by the occasional step backward but I hope you are excited about the journal as I am. If you have any comments, suggestions or observations on Spatial Demography please do not hesitate to contact me. The most important next step is the first one. I have now taken that step. I hope you will join me on the journey ahead.

Publisher's Note Springer Nature remains neutral with regard to jurisdictional claims in published maps and institutional affiliations.

\footnotetext{
${ }^{4}$ Again, please contact me if you have ideas, suggestions, and connections.

${ }^{5}$ Please let me know of books that you think would be suitable for review within the journal and/or if you are interested in writing a book review.
} 